\title{
BMJ Can patients really make an informed OPen choice? An evaluation of the availability of online information about consultant surgeons in the United Kingdom
}

\author{
Sarkhell Saadi Radha, ${ }^{1}$ Nick Caplan, ${ }^{2}$ Alan St Clair Gibson, ${ }^{2}$ Michael Shenouda, ${ }^{3}$ \\ Sujith Konan, ${ }^{3}$ Deiary Kader ${ }^{1}$
}

To cite: Radha SS, Caplan N, St Clair Gibson A, et al. Can patients really make an informed choice? An evaluation of the availability of online information about consultant surgeons in the United Kingdom. BMJ Open 2012:0:e001203

doi:10.1136/bmjopen-2012001203

- Prepublication history for this paper are available online. To view these files please visit the journal online (http://bmjopen.bmj.com).

Received 20 March 2012 Accepted 20 July 2012

This final article is available for use under the terms of the Creative Commons Attribution Non-Commercial 2.0 Licence; see http://bmjopen.bmj.com

\footnotetext{
${ }^{1}$ Department of Orthopaedics and Trauma, Queen Elizabeth Hospital, Gateshead, UK ${ }^{2}$ School of Life Sciences, Northumbria University, Newcastle upon Tyne, UK ${ }^{3}$ Department of Orthopaedics and Trauma, Chelsea and Westminster Hospital, London, UK
}

Correspondence to Dr Nick Caplan; nick.caplan@ northumbria.ac.uk

\section{ABSTRACT}

Objectives: The National Health Service (NHS) 'Choose and Book' online scheme, which allows patients to select the location and time of hospital appointments, has now been extended to include the option for patients to select a specific consultant to carry out any necessary treatment. The aim of this study was to determine whether there is sufficient online information about consultants or consultant-led teams for patients to make an informed choice regarding a specific consultant.

Design: A web-based analysis of the availability of information.

Setting: North of England.

Participants: Two hundred websites of orthopaedic surgeons.

Main outcome measures: The websites were analysed using a bespoke template that took into account recommendations of the 2010 UK Government white paper. Each website was scored in relation to the availability of specific content relating to each surgeon. Results: The majority of websites detailed authorship information (73.2\%), level of professional qualification $(98.5 \%)$ and area of general $(73.7 \%)$ and specialist $(93.3 \%)$ interest. However, approximately $50 \%$ of websites provided no information in relation to update cycle, involvement in teaching or research and patient satisfaction. Only five (2.6\%) of the websites presented death rates, and none indicated morbidity rates.

Conclusions: For patients to be able to make informed choices about their healthcare, surgeons need to ensure that sufficient information is available online, according to the identified limitations of the websites investigated in this study.

\section{INTRODUCTION}

The Department of Health's publication 'Better Information, Better Choices, Better Health: Putting Information at the Centre of Health' stressed the need for high-quality information about National Health Service (NHS) organisations to be available for

\section{ARTICLE SUMMARY}

Article focus

- The National Health Service 'Choose and Book' scheme has been in operation for nearly a decade.

- The success of the 'Choose and Book' policy depends on an adequate amount of online information being available to patients on individual consultants and consultant-led teams.

- The aim of this study was to investigate the availability of online information relating to consultants and consultant-led teams.

\section{Key messages}

- The majority of the websites examined included general information, such as each surgeon's professional qualification and areas of interest.

- Only half of the websites included more detailed information about involvement in teaching or research, or patient satisfaction.

Strengths and limitations of this study

- This study was the first to examine the availability of online information relating to individual consultants in the UK.

- The study focused on the websites of orthopaedic surgeons in the north of England, and future studies should extend this analysis to other fields of medicine, and across a wider geographic area. Future comparisons should also be made to information pertaining to private providers.

patients. This includes accurate, comprehensive and understandable information, along with provision for ease of accessibility. ${ }^{1}$ The quality of information available is also central to the overall quality of patient experience within the $\mathrm{NHS},{ }^{2}$ suggesting the importance of healthcare providers presenting all the necessary information appropriately, including accurate and relevant data and sources.

The electronic 'Choose and Book' referral system has been in operation since $2004 .^{3}$ This service was originally intended to give 
patients in England a choice of place, date and time of their first outpatient appointment. The government recently extended this service to include choosing between individual consultant-led teams. ${ }^{3}$ In order for patients to make such a choice, it is essential that they have high-quality, comprehensive and easily accessible information about relevant consultants available to them, thus making their choice appropriately informed.

A number of online information resources have been developed, which allow patients to compare various aspects of different hospitals. ${ }^{4}$ However, patients have reported that they would find information about individual specialties or surgeons more useful in choosing their healthcare provider for elective surgery. ${ }^{5}$ Such information, including surgical outcomes, has been available since 2004 in cardiac surgery. ${ }^{6}$ In other fields of medicine, where such information is not so readily available, patients will have to rely on the information contained within the websites of individual surgeons, either private or locally managed.

The 2008 national Omnibus survey reported that 65\% of British households have internet access compared to only $46 \%$ in $2002 .^{7}$ Currently, both healthcare providers and patients use internet-based sources regularly. ${ }^{8} 9$ Indeed, healthcare professionals have been increasingly faced with challenging questions from patients based on information found online, despite concerns about the quality of web-based information when it comes to health issues. ${ }^{8}{ }^{9}$ Despite the increasing proportion of the population that use the internet, the use of online information for healthcare choices is still relatively low. ${ }^{10}$ Interventions are clearly needed to improve the ability of patients to retrieve, interpret and use information about healthcare professionals. ${ }^{11}$ To ensure that patients can continue to make informed choices as their use of online information increases, it is necessary that this information is available consistently across all surgical fields, not just cardiac surgery. Indeed, this information has generally been criticised in recent years for not being timely, and having inadequate content. ${ }^{12}$

To the best of our knowledge, no studies have identified what information patients use in selecting the consultant they are referred to. Lim and Eldin ${ }^{13}$ reported that older people were more likely to choose a hospital if they think a consultant is performing the surgery, suggesting the involvement of a surgeon could be 'a proxy for expertise and quality of the clinical care'. Boyce et $\mathrm{al}^{5}$ found patients expressed that a key motivation for choice of hospital was knowing details of expertise (specialist doctors) within the hospital, suggesting the importance of the skills, experience and expertise of the individual consultants. It has been suggested that websites should also help develop trust within the patient by being provided by organisations that would not directly benefit from advertising a particular consultant. ${ }^{14}$

Despite the importance of information being available online to patients to allow them to make informed choices in terms of consultant-led teams, no research to date has examined whether such information is available in a consistent way across a range of consultants. The aim of this study was to evaluate the availability of consultant-specific online information to allow patients make appropriately informed choices.

\section{METHOD}

The names of 200 consultant orthopaedic surgeons across the north of England were selected to be included in the evaluation of the availability of online information. These names were obtained from representatives of the Royal College of Surgeons. In order to be included in the study, the consultants had to currently be:

A. employed within an NHS hospital in the north of England;

B. practising as a qualified consultant orthopaedic surgeon; and

C. registered with the Royal College of Surgeons.

An internet search was performed between May and August 2011 using the strategy derived by Biermann et al. ${ }^{15}$ Each orthopaedic consultant's full name was entered into the seven most commonly used English language search engines (applicable at the time of our search): AOL, Google, Lycos, MSN (Bing), Netscape, Askjeeves and Yahoo. The first 30 relevant resultant links were used for initial evaluation, as it has been previously suggested that subsequent results are usually duplicates. ${ }^{16}$ We assumed searches performed by the general population would be superficial approach searches as performed by novice, rather than expert, users. ${ }^{17-19}$

Websites that were found not to contain any relevant information were excluded. The relevant websites on each search engine were evaluated for suitability to be rated. From the websites returned by each search engine, the web page with the most information for each consultant, as per the assessment tool, was subsequently used for the study.

An assessment tool was developed and used in assessing website content and quality (table 1 ). This comprised two main parts. Part A was designed to answer questions on the websites themselves, including each website's accessibility, update cycle, availability of authorship information, type of author, target audience, and whether the website was used for any kind of promotion or advertisement. Part B was designed to analyse the availability of website content, focusing on information about individual surgeons. For part B, a template was produced with a view to gather as much information as possible about consultants, to include such items as are regularly used by medical staff for self-promotion (eg, Curriculum Vitaes) as well as those items that have been reported in the literature as being important to patients. An initial review of a selection of websites was used to identify typical items of information that are typically presented. These included their highest level of qualification, areas of general interest and/or any specialist interests, whether they were involved in research 
Table 1 Assessment tool/template used to assess (A) the descriptive content of each website and (B) the quality of information contained in each website that is relevant to the surgeon

\begin{tabular}{|c|c|}
\hline Item & Response categories \\
\hline \multicolumn{2}{|c|}{ Part A: Website description } \\
\hline Accessibility & $\begin{array}{l}\text { Easy to open, page not found, } \\
\text { no longer exists }\end{array}$ \\
\hline $\begin{array}{l}\text { Last date of update of } \\
\text { information }\end{array}$ & Yes/no; if yes, how old? \\
\hline $\begin{array}{l}\text { Availability of } \\
\text { authorship information }\end{array}$ & Yes/no \\
\hline Type of author & $\begin{array}{l}\text { Professional organisation, profit } \\
\text { organisation, educational } \\
\text { institution, instrument company, } \\
\text { club, others }\end{array}$ \\
\hline $\begin{array}{l}\text { Target audience } \\
\text { information }\end{array}$ & Yes/no \\
\hline $\begin{array}{l}\text { Type of target } \\
\text { audience }\end{array}$ & $\begin{array}{l}\text { General public, healthcare } \\
\text { providers, patients, insurers, } \\
\text { targeted workers }\end{array}$ \\
\hline \multicolumn{2}{|c|}{ Part B: Adequacy of content } \\
\hline Picture of surgeon & Yes/no \\
\hline Highest qualification & $\begin{array}{l}\text { Primary medical degree, } \\
\text { MRCS, FRCS, others }\end{array}$ \\
\hline $\begin{array}{l}\text { Area(s) of general } \\
\text { interest }^{*}\end{array}$ & Yes/no \\
\hline $\begin{array}{l}\text { Area(s) of specialist } \\
\text { interest(s) }\end{array}$ & Yes/no \\
\hline Mortality rate & Yes/no \\
\hline rate† & Yes \\
\hline Research & Yes/no \\
\hline Research publications & Yes/no \\
\hline Teaching & Yes/no \\
\hline $\begin{array}{l}\text { Management and } \\
\text { leadership skills }\end{array}$ & Yes/no \\
\hline Patient satisfaction & $\begin{array}{l}\text { Excellent, good, average, poor, } \\
\text { not given }\end{array}$ \\
\hline \multicolumn{2}{|c|}{$\begin{array}{l}{ }^{*} \text { The area(s) of interest include(s) descriptions such as, for } \\
\text { example, lower-limb surgery, upper-limb surgery, spinal surgery, } \\
\text { etc. The specialist interest(s) include(s) descriptions such as } \\
\text { sports injuries, soft tissue surgery, arthroscopic surgery, trauma } \\
\text { surgery, etc. } \\
\text { †Morbidity: complications related to orthopaedic procedure(s). }\end{array}$} \\
\hline
\end{tabular}

projects and/or whether they had published research, morbidity rates, death rates and levels of patient satisfaction, and whether a photograph of the surgeon was available on the website. The websites were also examined to determine whether surgeons were involved in teaching or had any management experience. Prior to the main website analysis, the assessment template was reviewed by clinical staff outside of the research team, including a consultant surgeon, a research physiotherapist, academic researchers, junior and senior medical doctors and nurses $(n=18)$, to ensure that all relevant items had been included.

All data were entered into a spread sheet in Microsoft Excel. For each item illustrated in table 1, frequencies for each scoring category (eg, yes/no) were determined.
These frequencies were also expressed as a percentage of either the total sample, or a relevant smaller sample. For those websites that reported patient satisfaction, associations between satisfaction score (1=poor, 2=average, $3=$ good, 4=excellent) and involvement in research, publication of research and involvement in teaching were determined using $\chi^{2}$ analyses. All $\chi^{2}$ analyses were performed in SPSS (V. 19, IBM). The required level for statistical significance was set at $\mathrm{p}<0.05$.

\section{RESULTS}

\section{Part A: analysis of description of website}

Websites for the vast majority of surgeons (194, 97.0\%) were easily accessible. Six (3.0\%) were not accessible, either because relevant web pages were not found within the first five results in each of the search engines, or because pages such as social media, dictionary or a completely different person's profile were found.

In terms of the availability of authorship information, $142(73.2 \%)$ websites had authorship information described on the website. The authors of the websites were variable and included professional organisations (21, 14.8\%), instrument companies $(39,27.5 \%)$, educational institutions $(10,7.0 \%)$, for-profit organisations $(7,4.9 \%)$ and others such as advertisement companies $(65,45.8 \%)$.

Eighty-six (44.3\%) websites did not state the last date of website update (table 2). Of those that did, most were updated between 13-18 months ago (40, 20.6\%). One hundred and eighty-three $(94.3 \%)$ websites specified the target audience (table 3), the vast majority of which were aimed at patients and the general public.

\section{Part B analysis of website content}

The second part of this study looked at the quality of information available on individual surgeons. A photograph of the surgeon was not available in 15 (7.7\%) websites. Almost all the websites studied provided some detail of qualifications of the surgeons (191, 98.5\%), with the majority $(185,95.4 \%)$ stating their highest level of qualification as Fellow of the Royal College of Surgeons (FRCS). Two (1.0\%) included primary medical qualifications as the highest academic recognition received, with four $(2.1 \%)$ stating other academic qualifications.

Table 2 Frequency (\%) of websites that indicated last date of update

\begin{tabular}{ll}
\hline Not stated & Frequency \\
$0-6$ months & $86(44.3 \%)$ \\
$7-12$ months & $17(8.8 \%)$ \\
$13-18$ months & $28(14.4 \%)$ \\
$19-24$ months & $40(20.6 \%)$ \\
$2-3$ years & $11(5.7 \%)$ \\
\hline
\end{tabular}


Table 3 Frequency (\%) of websites that targeted specific types of audiences.

\begin{tabular}{lr}
\hline & Frequency \\
\hline Not stated & $11(5.7 \%)$ \\
General public & $139(71.6 \%)$ \\
Healthcare providers & $98(50.5 \%)$ \\
Patients & $126(64.9 \%)$ \\
Insurers & $21(10.8 \%)$ \\
Target workers & $9(4.6 \%)$ \\
\hline
\end{tabular}

Each row is not mutually exclusive as some websites targeted more than one type of audience.

None of the websites presented morbidity rates (defined as any postoperative complication directly related to the procedure such as infection, neurovascular damage, dislocation, stiffness, etc.); however, death rates from a few procedures were mentioned on five $(2.6 \%)$ websites.

Less than half of the websites $(85,43.8 \%)$ detailed involvement by the surgeon in teaching or give any indication that might reflect on teaching skills, such as teaching qualification(s) of the surgeon. The mean patient satisfaction score for those involved in teaching was $2.5 \pm 0.5$, and $2.1 \pm 0.3$ for those not involved in teaching. $\chi^{2}$ analysis showed a significant association between involvement in teaching and patient satisfaction $\left(\chi^{2}(2)=\right.$ 17.837, $\mathrm{p}<0.001)$, suggesting that surgeons involved in teaching received higher patient satisfaction scores than those not involved in teaching. Sixty-three websites $(32.5 \%)$ provided details of any management and/or leadership skills relating to the surgeon.

Information in relation to general areas of interest was available on $143(73.7 \%)$ websites, and a higher proportion of websites included details of specialist areas of interest $(181,93.3 \%)$. Approximately half of all websites provided details of whether surgeons were involved in research, or evidence of involvement in publication of research (table 4). The mean patient satisfaction score for those involved in research was $2.2 \pm 0.4$, and 2.6 \pm 0.5 for those not involved in research. $\chi^{2}$ analysis showed a significant association between involvement in research and patient satisfaction $\left(\chi^{2}(2)=15.097, \mathrm{p}<0.01\right)$. The mean patient satisfaction score for those who publish research was $2.2 \pm 0.4$, and $2.5 \pm 0.5$ for those not publishing research. $\chi^{2}$ analysis showed a significant association between involvement in research and patient satisfaction $\left(\chi^{2}(2)=10.118, p<0.01\right)$. These findings suggest that those involved in research or publishing research receive

Table 4 Frequency (\%) of websites indicating involvement in research and/or publishing of research

\begin{tabular}{llr}
\hline & Yes & \multicolumn{1}{c}{ No } \\
\hline Involvement in research & $96(49.5 \%)$ & $98(50.5 \%)$ \\
Publications & $92(47.2 \%)$ & $102(52.6 \%)$ \\
\hline
\end{tabular}

Table 5 Frequency (\%) of websites that stated level of patient satisfaction

\begin{tabular}{lc}
\hline & Frequency \\
\hline Excellent & $0(0 \%)$ \\
Good & $30(15.5 \%)$ \\
Average & $65(33.5 \%)$ \\
Poor & $1(0.5 \%)$ \\
Not given & $98(50.5 \%)$ \\
\hline
\end{tabular}

lower patient satisfaction scores than those not involved in research.

Patient satisfaction was categorised as excellent, good, average, poor or not given. Half of the websites gave no information on patient satisfaction $(98,50.1 \%)$. Thirty (15.5\%) websites provided good ratings for patient satisfaction, and $65(33.5 \%)$ websites showed average ratings (table 5).

\section{DISCUSSION}

\section{Principal findings}

The majority of websites studied were accessible; however, there are questions regarding the authorship and availability of the last date of update. This is particularly important as studies have found that patients prefer websites run by recognisable healthcare organisations or professional groups. ${ }^{20}{ }^{21}$ Several essential criteria have been described for health websites, including disclosure of site owner, authors and update cycle. ${ }^{22}$ Items such as documenting the target audience have been regarded as an important aspect of successful online resources and the website content should be tailored in a way such that the target audience should always be emphasised. ${ }^{23}$ Nearly half of the websites analysed targeted other sectors, not patients. This could create confusion and reduce the specificity of websites to patient needs.

With regard to individual surgeons, having a photograph of the surgeon on the website is important to allow patients to recognise whom they will be treated by. The presence of profile pictures in websites has previously been linked to more accurate estimation of personality traits. ${ }^{24}{ }^{25}$ Hassin and Trope also found that personality could be judged purely on the basis of a facial photograph. ${ }^{26}$ Physical features such as the size of a person's eyes and the shape of their mouth can also influence perceptions of personality. ${ }^{27}$ Nearly all websites provided some information about the qualifications of the surgeon, with the majority stating Fellowship of the Royal College of Surgeons as the highest level attained. Details of a surgeon's qualifications might influence patient confidence and trust in choosing an individual surgeon. Good qualities such as work ethic, reliability, specific knowledge and skills have been linked to having qualifications. ${ }^{28}$

Only a small number of websites reported death rates and none reported morbidity rates. Magee $e t a l^{29}$ found that the majority of patients do not find this information 
useful in making choices about their healthcare as it was not seen as linking with clinical quality or was suggested by the patients as being 'frightening'. Conversely, Burge et $a l^{031}$ report that patients do consider death rates to be important for choice. Despite this finding, some independent websites report death rates for individual hospitals. ${ }^{32}$ If such figures are to be published in the future for individual surgeons or consultant-led teams, it could be useful for patients to also know the number of surgical procedures performed by each consultant so that these rates can be presented as a percentage of each consultant's total number of operations. Depending on a consultant's area of specialism, it may be that they are referred specific cases which are of higher risk. By presenting non-risk-adjusted death rates could lead to some surgeons appearing to patients, through misinterpretation, as being riskier. Reported death rates should be fully risk-adjusted to ensure that appropriate comparisons can be made between different surgeons, and to avoid higher-risk patients being declined surgery in an attempt to maintain low death rates. ${ }^{6}$

Only about half of the websites analysed gave any indication of involvement of the surgeon in teaching related activities. This attribute is a necessity based on General Medical Council guidelines and indicates good medical practice. ${ }^{33}$ Improved outcomes following surgery have been linked to preoperative patient education, ${ }^{34}$ suggesting the importance of developing teaching skills. Conversely, involvement in teaching might suggest that surgical procedures are performed by more junior clinical staff under consultant supervision. Older patients have reported as being more likely to choose where they are referred based on whether a consultant will perform the actual surgical procedure, ${ }^{13}$ and thus involvement in teaching by the consultant might modify patient choice to avoid a teaching institution. Our findings suggest that those surgeons who are involved in teaching received higher patient satisfaction scores. This finding must be interpreted with caution, however, as the statistical analysis could only be performed on those websites which reported patient satisfaction, and it is not known whether all surgeons who are involved in teaching actually reported this on their websites. Clearly, this association should be examined in more detail in future studies.

Only about half of the websites investigated provided details of engagement by the surgeon in research or the publication of peer-reviewed articles. The field of medicine is changing continuously and with the development of new techniques and procedures, research has become fundamental to surgical practice. Research is vital in providing the new knowledge needed to improve health outcomes and reduce inequalities. ${ }^{3}$ Parboosingh $^{35}$ suggested that there is strong public demand for doctors to keep up-to-date, stressing the importance of continuing professional development and even a need for periodic reassessment. Although many of these consultants are likely to be involved in research activities, it is clear that this is not adequately portrayed to patients. It is interesting to note that our data suggest those surgeons involved in research or publishing research received slightly lower patient satisfaction scores than those not reporting involvement in research. As for the association between teaching and patient satisfaction, these associations should be read with caution due to the uncertainty about whether every surgeon involved in research or publishing actually reported it on their web page.

Almost half of the websites analysed did not publish any information on patient satisfaction. The reputation of healthcare organisations for commitment to quality patient care still stands as the main criteria for patients in choosing healthcare providers. ${ }^{36}{ }^{37}$ Measuring and incorporating patient satisfaction to the culture of healthcare organisations should be a strategic goal for all healthcare providers. ${ }^{36}$ Lee $^{38}$ reported that $90 \%$ of hospitals currently have some form of patient satisfaction survey and most of the results are published in a national or regional database. If a trust fails to maintain good patient satisfaction, it will risk rendering poorquality care and loss of service consumers. ${ }^{39}$ Contrary to this, Fenton et $a l^{40}$ identified that patients who were more satisfied had a $26 \%$ increased risk of mortality. They cautioned against the use of patient satisfaction without further investigation.

\section{Strengths and limitations of study}

To the best of our knowledge, this is the first study to conduct a comprehensive analysis of the availability of web-based information relating to individual consultant surgeons in any field of medicine. The study looked at the profiles for consultant orthopaedic surgeons only, and did not consider other surgical fields.

The assessment tool used in this study to rate each website was developed in line with recommendations from the Government's white paper, ${ }^{3}$ and reviewed by a group of clinicians and academics. This tool could be developed further for future studies through the involvement of patient groups to determine which factors they consider to be important in accessing the information about consultants in order to exercise choice.

\section{Policy implications and future research}

Our study has demonstrated a lack of available public information offered by healthcare providers' websites on consultant surgeons. Such information is essential for patients to be able to make an informed choice. ${ }^{41}$ While information on waiting times and technical issues are easy to obtain, other performance indicators such as quality of care and safety issues are more difficult to obtain and interpret. ${ }^{42}$ Our findings are consistent with evidence from others, suggesting that patients are insufficiently informed to be able to exercise choice effectively. ${ }^{43}$

Future research should examine differences in the availability of online information in other fields of medicine and identify mechanisms that can be introduced to improve consistency in information provision across the 
healthcare sector to help improve the patient experience. Further research is also needed to evaluate not just the availability of online information, but also the quality, accuracy and reliability of this information, and consistency of information reporting across different trusts. Comparisons should also be made between the information available on both public and private providers.

Although there are a variety of different types of information available to patients to help them make healthcare choices, it is not clear as to how each of these items link to patient satisfaction and patient outcomes, and our analyses of the associations between patient satisfaction and involvement in teaching, research or publishing are limited by lack of consistency in reporting each item of information. Further research is needed to determine how different items of information link to patient satisfaction. For valid and generalisable results to be obtained, the mechanisms of obtaining patient satisfaction in different trusts will need to be standardised.

This study was an evaluation of the information availability in traditional web pages. In recent years, use of social media has seen a rapid expansion with the majority of people who surf the internet using social media (eg, blogs, social networks, etc). ${ }^{44}$ Social media clearly, therefore, has a potential role to play in shaping how future healthcare choices are made. ${ }^{45}$ Future research should identify how patients use social media in making choices relating to their healthcare.

\section{CONCLUSIONS}

Despite the government policy encouraging patients to make more choices in relation to healthcare, our findings demonstrate that there is a paucity of data available to patients through online media to allow them to make informed choices about which consultant they wish to be referred to. This finding highlights the need for standardisation across websites that provide information about consultants to patients, or indeed, the need for a centralised online tool that can allow patients to access all the required information about available consultants. The most notable areas that websites should look to improve are in the reporting of website update cycle, involvement in teaching, research and the publication of research, and patient satisfaction, all of which were only reported by about half of all websites.

Acknowledgements We would like to acknowledge Dr Katherine Sanderson for her support during the study.

Contributors SR, NC, DK, ASCG - contributed to the initial conception of the study, the development of the protocol and the design of the design of the website assessment template; SR - obtained ethical approval for the study, performed the website analyses and completed all data entry; NC—completely analysed the data; SR, NC, DK, ASCG, MS, SK - contributed to the interpretation of the data; SR-wrote the first draft of the manuscript; NC, DK, ASCG, MS, SKcritically reviewed the draft manuscript; NC—contributed additional text in subsequent revisions of the manuscript; SR, NC, DK, ASCG, MS, SK-approved the final version of the manuscript. NC and DK—are guarantors for the study.
Funding This research received no specific grant from any funding agency in the public, commercial or not-for-profit sectors.

Competing interests All authors have completed the Unified Competing Interest form at www.icmje.org/coi_disclosure.pdf (available on request from the corresponding author) and declare that (1) no authors received funding from any company for the submitted work; (2) no authors have any relationships with companies that might have an interest in the submitted work in the previous 3 years; (3) their spouses, partners or children have no financial relationships that may be relevant to the submitted work; and (4) no authors have any non-financial interests that may be relevant to the submitted work.

Ethics approval Ethical approval was obtained from the University of Teesside ethical committee. Consultant names were used only to identify websites and gather information with regard to their content. The names were not included in the template or in any other part of the study. There was no mention of the names of the websites studied, and the data were collected through a preprepared questionnaire examining the content of the websites without the use of any quotations from the websites themselves. All information evaluated was in the public domain. We therefore were not required to seek consent specifically from the individual consultants or websites.

Provenance and peer review Not commissioned; externally peer reviewed.

Data sharing statement The Corresponding Author has the right to grant on behalf of all authors and does grant on behalf of all authors, a worldwide licence to the Publishers and its licensees in perpetuity, in all forms, formats and media (whether known now or created in the future), to (i) publish, reproduce, distribute, display and store the Contribution, (ii) translate the Contribution into other languages, create adaptations, reprints, include within collections and create summaries, extracts and/or abstracts of the Contribution, (iii) create any other derivative work(s) based on the Contribution, (iv) exploit all subsidiary rights in the Contribution, (v) the inclusion of electronic links from the Contribution to third-party material where-ever it may be located; and (vi) licence any third party to do any or all of the above.

\section{REFERENCES}

1. Department of Health. Choose and book: patient's choice of hospital and booked appointment - policy framework for choice and booking at the point of referral, 2004. http://www.dh.gov.uk/prod_consum_dh/ groups/dh_digitalassets/@dh/@en/documents/digitalasset/ dh_4088352.pdf (accessed 13 Mar 2012).

2. Coulter A, Entwistle V, Gilbert D. Sharing decisions with patients: is the information good enough? BMJ 1999;318:318.

3. Department of Health. Equity and excellence: liberating the NHS, 2010 http://www.dh.gov.uk/prod_consum_dh/groups/ dh_digitalassets/@dh/@en/@ps/documents/digitalasset/dh_117794. pdf (accessed 13 Mar 2012).

4. Dixon A, Robertson R, Bal R. The experience of implementing choice at point of referral: a comparison of the Netherlands and England. Health Econ Policy Law 2010;5:295-317.

5. Boyce T, Dixon A, Fasolo B, et al. Choosing a high quality hospital: the role of nudges, scorecard design and information. The Kings Fund: London, 2010.

6. Bridgewater B, Keogh B. Surgical 'league tables'. Heart 2008;94:936-42.

7. Office for National Statistics. Internet access - households and individuals, 2008. http://www.ons.gov.uk/ons/rel/rdit2/ internet-access--households-and-individuals/2008/index.html (accessed 13 Mar 2012).

8. Crocco AG, Villasis-Keever M, Jadad AR. Analysis of cases of harm associated with use of health information on the internet. JAMA 2002;287:2869-71.

9. Helft PR, Hlubocky F, Daugherty CK. American oncologists' views of internet use by cancer patients: a mail survey of American Society of Clinical Oncology members. J Clin Oncol 2003;21:942-7.

10. Department of Health. Report on the National Patient Choice Survey. England; $2010 \mathrm{Feb}$, http://www.dh.gov.uk/prod_consum_dh/ groups/dh_digitalassets/documents/digitalasset/dh_117096.pdf (accessed 5 June 2012).

11. Passarani I. What do patients want of performance information? BMJ 2010;341:c6955. 
12. Edgman-Levitan S, Cleary PD. What information do consumers want and need? Health Aff 1996;15:42-56.

13. Lim JNW, Edlin R. Preferences of older patients and choice of treatment location in the UK: a binary choice experiment. Health Pol 2009;91:252-7.

14. Marshall M, McLoughlin V. How do patients use information on providers? BMJ 2010;341:1255-7.

15. Biermann JS, Golladay GJ, Greenfield ML, et al. Evaluation of cancer information on the Internet. Cancer 1999;86:381-90.

16. Hargrave DR, Hargrave UA, Bouffet E. Quality of health information on the Internet in pediatric neuro-oncology. Neuro Oncol 2006;8:175-82.

17. Tsai MJ, Tsai C. Information searching strategies in web-based science learning: the role of Internet self-efficacy. Innov Ed Teach Int 2003;40:43-50.

18. Biggs J. Approaches to learning: nature and measurement of. In: Husen T, Postlethwaite TN, eds. The international encyclopedia of education. 2nd edn. Vol. 1. Oxford: Pergamon, 1994:319-22.

19. Marton F. Beyond individual differences. Educ Psychol 1983:3:289-303.

20. Eysenbach G, Köhler C. How do consumers search for and appraise health information on the world wide web? Qualitative study using focus groups, usability tests, and in-depth interviews. BMJ 2002;324:573-7.

21. Schwartz KL, Roe T, Northrup J, et al. Family medicine patients' use of the internet for health information. J Am Board Fam Med 2007;19:39-45.

22. Boyer C, Selby M, Scherrer JR, et al. The health on the net code of conduct for medical and health websites. Comp Biol Med 1998;28:603-10.

23. MacCulloch R, Nyhof-Young J, Nicholas D, et al. Development of an online information and support resource for adolescent idiopathic scoliosis patients considering surgery: perspectives of health care providers. Scoliosis 2010;13:101-4.

24. Gosling SD, Gaddis D, Vazire S. Personality impressions based on Facebook profiles. In Proceedings of the International Conference on Weblogs and Social Media; 26-28 March 2007, Boulder, Colorado, USA. http://www.icwsm.org/papers/3-Gosling-GaddisVazire.pdf (accessed 14 Mar 2012).

25. Zebrowitz LA, Collins MA. Accurate social perception at zero acquaintance: the affordances of a Gibsonian approach. Pers Soc Psychol Rev 1997;1:204-22.

26. Hassin R, Trope Y. Facing faces: studies on the cognitive aspects of physiognomy. J Pers Soc Psychol 2000;78:837-52.
27. Kahnman D. A perspective on judgment and choice: mapping bounded rationality. Am Psychol 2003;58:697-720.

28. Keating J, Nicholas T, Polesel J, et al. Qualifications use for recruitment in the Australian labour market. Adelaide: National Centre for Vocational Education Research, 2005.

29. Magee H, Davis LJ, Coulter A. Public views on healthcare performance indicators and patient choice. J Royal Soc Med 2003;96:338-42.

30. Burge P, Devlin N, Appleby J, et al. London patient choice project evaluation. RAND: London, 2005.

31. Burge P, Devlin N, Appleby J, et al. Understanding patient choices at the point of referral. RAND: London, 2006.

32. Jacobson B, Mindell J, McKee M. Hospital mortality league tables. BMJ 2003;326:777.

33. General Medical Council. Good medical practice, 2009. http://www. gmc-uk.org/guidance/good_medical_practice.asp (accessed 13 Mar 2012).

34. Jones S, Alnaib M, Kokkinakis M, et al. Pre-operative patient education reduces length of stay after knee joint arthroplasty. Ann R Coll Surg Engl 2011;93:71-5.

35. Parboosingh J. Revalidation for doctors should reflect doctors' performance and continuing professional development. BMJ 1998;317:1094-5

36. Stavins CL. Developing employee participation in the patient satisfaction process. J Healthc Manag 2004;49:135-9.

37. Luft HS, Garnick DW, Mark DH, et al. Does quality influence choice of hospital? JAMA 1990;263:2899-906.

38. Lee F. If Disney ran your hospital: 9 1/2 things you would do differently. Bozeman MT: Second River Healthcare Press, 2004.

39. Press I. Patient satisfaction: understanding and managing the experience of care. 2nd edn. Chicago: Health Administration Press, 2006.

40. Fenton JJ, Jerant AF, Bertakis KD, et al. The cost of satisfaction: a national study of patient satisfaction, health care utilization, expenditures, and mortality. Arch Intern Med 2012;172:405-11.

41. Appleby J, Harrison A, Devlin N. What is the real cost of more patient choice? Kings Fund: London, 2003.

42. Coulter A, Ellins J. Effectiveness of strategies for informing, educating, and involving patients. BMJ 2007;335:24-7.

43. Entwistle VA, Sheldon TA, Sowden A, et al. Evidence-informed patient choice. Int J Tech Assess Health Care 1998;14:212-25.

44. Kaplan AM, Haenlein M. Users of the world, unite! The challenges and opportunities of social media. Bus Horiz 2010;53:59-68.

45. Hawn C. Take two aspirin and tweet me in the morning: how Twitter, Facebook, and other social media are reshaping health care. Health Aff 2009;28:361-8. 